\title{
Zwei neue Cetoniden von der Molukkeninsel Dammer.
}

\author{
Beschrieben von
}

\section{Dr. G. Kra at z.}

Protaetia cupreola: Cupreo-viridis, subtus nitida, supra obscure cupreo-aenea, subnitida, clypeo antice elevato, medio emarginato, minus dense punctato, thorace utrinque punctis lineolisque albis fossulisque parum perspicue impressis, disco parce punctato, elytris parce albo-punctatis, disco pone medium lineis nonnullis impressis, lateribus lineatim parum dense punctatis, pygidio utrinque dense albo-piloso, pedibus viridulis, tibiis anticis feminae distinctius bidentatis, dente tertio (basali) maris vix perspicuo. - Long. 18 mill. Von der Molukken-Insel Dammer (Dr. Staudinger).

Der Prot. acuminata nahe verwandt, aber gröfser, flacher, unten glänzend-, oben dunkel-kupfrig, wenig glänzend, keinesfalls eine locale Rasse des acuminatus. Der Vorderrand des Clypeus ist stärker erhaben, in der Mitte leicht ausgebuehtet; die Punktirung des Kopfes ist vorn nicht dicht, sondern ziemlich weitläufig; die Stirn ist in der Mitte schwielig erhaben, ebenfalls weitläufiger punktirt als bei acum. Das Halssch. ist ganz ähnlich gebaut wie bei acuminata, 3 Paar Punkte vor der Mitte der leicht erhabenen Mittellinie weifs undeutlich, ebenso mehrere längliche Punkte nicht weit vom Rande, zwischen den Vorder- und Hinterecken; einige flache, unbestimmte Eindrücke durch den dunkleren Toment derselben angedeutet; die Punktirung jederseits auf der Schwiele ziemlich weitläufig; die Mittellinie nicht so gleichmälsig glatt wie bei acum. Schildchen jederseits am Rande punktirt. Auf dem Eindruck hinter der Mitte der Fld. sind meist nur 2-3 Streifen bemerkbar (bei acum. wohl 5); am Rande stehen 4-5 wenig hervortretende, weifse Flecke, neben der sehr deutlich ausgezogenen Spitze einer; einige andere auf dem Discus machen sich wenig bemerkbar, die Punkte stehen weitläufiger als bei acum. Das Pygidium ist jederseits dicht grau befilzt. Segment 2-4 zeigen einen weifslichen Fleck hinten an den Aufsenecken und einen weifsen Querfleck an der Basis jederseits vor der Mitte. Die Punktirung stärker und sparsamer als beim $q$, auf dem letzten Segment stärker als beim ㅇ. Die beiden Endzähne der Vorderschienen sind beim $q$ kräftiger als beim $\widehat{o}$; bei diesem ist der erste Zahn bisweilen kaum angedeutet. 
Clinteria nigra: Nigra, nitida, thoracis disco parcius, lateribus minus crebre punctatis, elytris punctato-striatis, bicostatis, costa dorsali magis perspicua, spatio suturali basin versus latius laevi, sutura pone medium magis elevata, pygidio dense striolato, abdomine fere laevigalo, tibiis anticis tridentatis, dente primo maris parum perspicuo. - Long. 12-13 mill.

Eine durch tiefe schwarze Färbung und Glanz sehr ausgezeichnete Art, welche in Grölse und Habitus der Pseudoclinteria permutans am nächsten steht. Der Clypeus ist vorn deutlich ausgebuchtet, oben wenig dicht, ziemlich seicht punktirt, die Stirn schwach erhaben, glatt, die Seiten des Kopfes deutlich punktirt. Das Halssch. ist äbnlich wie bei permutans gebaut, der Mittellappen aber breiter; der Discus ist ziemlich flach, weitläufig punktirt, nach vorn und an den Seiten etwas dichter. Die Fld. sind punktirtgestreift, eine Rippe unweit der Naht merklich stärker als die folgende, beide am Endbuckel verbunden; der Raum zwischen der Naht und der Rippe ist glatt, ein feiner Nahtstreif an der Basis angedeutet, hinter der Mitte erhebt sich die Naht allmählich stärker; der Raum am Endbuckel ist mit grofsen, seichten Punkten besetzt. Das Pygidium ist dicht gestrichelt, die Strichelchen sind bisweilen bogenförmig. Das Abdomen ist fast glatt, beim $\widetilde{\sigma}$ sanft flachgedrückt. Der Mesosternalfortsatz ist ziemlich stark nach vorn und unten vorgezogen. Die Vorderschienen sind dreizähnig; der erste Zahn ist beim $\widetilde{\sigma}$ weiter vom 2 ten entfernt als beim 우 und wenig bemerkbar.

Von der Molukkeninsel Dammer (Dr. Staudinger).

Diese ausgezeichnete Art ist die erste bekannt gewordene von den Molukken.

\section{Kleinstes Stück von Helionica Westwoodi Thoms. (siehe D. E. Z. 1898, p. 215).}

Nachträglich ist mir das kleinste Stück von Hel. Westwoodi zugegangen, aus derselben Sendung stammend wie die übrigen a.a. O. besprochenen Stücke. Dasselbe ist 14 mill. lang, Länge der Fld. 9 mill., des Thorax 10 mill., des Kopfhornes 9 mill., des Thoraxhornes $3 \frac{1}{2}$ mill., Entfernung des Höckers von der Thoraxbasis 1 mill., von der Spitze 3 mill. Der Thorax ist grün, das Horn nur gegen die Spitze fein kupfrig. Der von mir p. 216 beschriebene viridicollis hatte keinen Höcker an der Unterseite des Thoraxhornes, der kleinste Westwoodi dagegen einen sehr deutlichen. 


\section{$2 \mathrm{BHL}$ Biodiversity Heritage Library}

Kraatz, G. 1899. "Zwei neue Cetoniden von der Molukkeninsel Dammer." Deutsche entomologische Zeitschrift 1899(2), 237-238.

https://doi.org/10.1002/mmnd.48018990204.

View This Item Online: https://www.biodiversitylibrary.org/item/103426

DOI: https://doi.org/10.1002/mmnd.48018990204

Permalink: https://www.biodiversitylibrary.org/partpdf/235764

\section{Holding Institution}

Harvard University, Museum of Comparative Zoology, Ernst Mayr Library

\section{Sponsored by}

Harvard University, Museum of Comparative Zoology, Ernst Mayr Library

\section{Copyright \& Reuse}

Copyright Status: Public domain. The BHL considers that this work is no longer under copyright protection.

This document was created from content at the Biodiversity Heritage Library, the world's largest open access digital library for biodiversity literature and archives. Visit BHL at https://www.biodiversitylibrary.org. 